\title{
DiGA-ME AGORA... O DEPOIMENTO SEM DANO EM ANÁLISE
}

\author{
Leila Maria Torraca de Brito*
}

\section{Resumo}

$\mathrm{O}$ artigo aborda, por meio de discussão teórica, o denominado Depoimento sem Dano, procedimento defendido por alguns para se obter testemunhos de crianças e de adolescentes. Trata-se da possibilidade de crianças e jovens, acomodados em salas especialmente projetadas com câmeras e microfones, serem inquiridos em processos judiciais por psicólogos ou assistentes sociais. No artigo são expostos argumentos apresentados por aqueles que defendem a implantação do Depoimento sem Dano em território nacional, como proposto em projeto de lei que tramita no Senado Federal, enfocando-se também motivos dos que contestam essa prática. São apresentadas, ainda, discussões empreendidas por profissionais de outros países, que analisam a execução de trabalhos similares. Conclui-se pela inadequação desta prática, especialmente quando vista como atribuição de psicólogos.

Palavras-chave: depoimento sem dano; depoimento infanto-juvenil; psicologia jurídica.

\section{AbSTRaCt}

\section{TELL ME NOW... No DAMAGE DEPOSITION UNDER ANALYSIS}

Under a theoretical argumentation, this article approaches the so called - "no damage deposition", a procedural act that some defend to obtain testimonies from children. This is a possibility for child and youngsters, settled in special rooms equipped with video cameras and microphones to be interrogated, in judicial proceedings, by psychologists and social assistants. In this paper, we present the arguments of those who look forward to its approval as a statute, as it has already been proposed, in the Brazilian Senate, and also of others who oppose this practice. Herein are described arguments from professionals from other countries in the world, who analyze their similar procedures. We conclude that this practice is inadequate, especially when seen as an attribution of psychologists.

Keywords: no damage deposition; youth deposition; juridical psychology.

* Professora Adjunta do Instituto de Psicologia da Universidade do Estado do Rio de Janeiro (UERJ). 


\section{INTRODUÇÃO}

Atualmente, ano de 2008, tramita no Senado Federal projeto de lei que dispõe sobre a inquirição de crianças e de adolescentes em processos judiciais (PLC 035/ 2007), propondo alteraçôes tanto no Estatuto da Criança e do Adolescente, como no Código de Processo Penal Brasileiro para que esta prática seja regulamentada.

Nas justificativas para aprovação do citado projeto alude-se, com freqüência, ao artigo $12^{\circ}$ da Convenção Internacional sobre os Direitos da Criança, artigo que destaca o direito de a criança ser ouvida - quer diretamente, quer por intermédio de um representante ou órgão apropriado - em todo processo judicial que a afete. Assim, evocando esse artigo da Convenção, bem como o artigo 227 da Constituição da República Federativa Brasileira e o princípio da dignidade da pessoa humana, presente em nossa Carta, diversos profissionais vêm defendendo o testemunho infanto-juvenil em processos judiciais.

Favoráveis à inquirição ${ }^{1}$ de crianças e adolescentes especialmente por meio do denominado Depoimento sem $\mathrm{Dano}^{2}$, alguns operadores do direito indicam que tal procedimento deveria ser realizado por psicólogos ou assistentes sociais. Como descreve Daltoé Cezar (2007a), magistrado gaúcho a quem se atribui a idéia de implantação do Depoimento sem Dano e que foi agraciado, em dezembro de 2006, com menção honrosa no prêmio Innovare, este depoimento é: "uma alternativa para inquirir crianças e adolescentes vítimas de abuso sexual em juízo, [...] implementada na cidade de Porto Alegre desde maio de 2003" (Daltoé Cezar, 2007a: 61).

Explica o autor que, segundo esse modelo, crianças e adolescentes são ouvidos em uma sala aconchegante, especialmente preparada para o atendimento de menores de idade, equipada com câmeras e microfones para se gravar o depoimento. O Juiz, o Ministério Público, os advogados, o acusado e os servidores judiciais assistem ao depoimento da criança por meio de um aparelho de televisão instalado na sala de audiências. No Rio Grande do Sul, o profissional designado pelo Juiz para inquirir as crianças costuma ser o assistente social ou o psicólogo, que permanece com fone no ouvido para que o Juiz possa indicar perguntas a serem formuladas à criança.

Daltoé Cezar (2007b: 73) expõe que "o momento processual do Depoimento sem Dano é uma audiência de Instrução”, motivo pelo qual cabe ao Juiz decidir sobre as perguntas a serem formuladas. O técnico incumbido de apresentar as questões para a criança teria atuação semelhante à de um intérprete. Explica também o Juiz que, ao final do Depoimento sem Dano, cabe ao técnico "a coleta de assinaturas no termo de audiência” (Daltoé Cezar, 2007b: 76). 
Com a gravação do depoimento uma cópia é anexada ao processo, sendo desnecessário repetir a inquirição. $\mathrm{O}$ magistrado informa que esta proposta, uma iniciativa do Poder Judiciário do Rio Grande do Sul, tem como base o procedimento que se realiza na chamada Câmara de Gesell, utilizada por alguns psicólogos em trabalho clínico.

Há que se destacar que até o presente, no sistema de justiça nacional, geralmente a escuta de crianças e de adolescentes vem sendo feita por assistentes sociais e psicólogos que integram as equipes técnicas dos juízos ou por serviços especializados. Essa escuta, entretanto, se dá no decorrer de atendimentos psicológicos, ou sociais, da forma como o profissional considerar mais adequada, podendo utilizar técnicas e instrumentos que julgue apropriados.

Como se pode observar, a preocupação em assegurar os direitos infantojuvenis dispostos na Convenção Internacional sobre os Direitos das Crianças (1989) e especificados no Estatuto da Criança e do Adolescente (1990) vem sendo evocada na exposição de motivos de diversos projetos de lei, na busca bem intencionada de respostas às dúvidas e impasses que se apresentam em situações do contexto contemporâneo. No entanto, também tem sido corrente o alerta de alguns pesquisadores quanto à profusão de textos, propostos em distintos países, que têm por mote o interesse da criança, acarretando o que muitos consideram um verdadeiro "frenesi legislativo", como classifica Théry (1998: 18). A autora recomenda, portanto, exame cuidadoso das indicaçôes contidas em projetos de lei direcionados à população infanto-juvenil, sugestão que se optou por seguir ao eleger como objeto de análise do presente artigo o denominado Depoimento sem Dano. Não se pode deixar de assinalar que o trâmite do projeto no Poder Legislativo gerou acaloradas discussões, quando vozes discordantes passaram a se pronunciar.

\section{Algumas JUSTIFICATIVAS PARA A IMPLANTAÇÃo DO DEPOIMENTO SEM DANO}

Um dos argumentos para a inquirição judicial de crianças e de adolescentes seria a dificuldade de se obter provas em algumas situaçôes que ocorrem com os mesmos, fato que acarretaria, conseqüentemente, baixo número de condenações de adultos que podem ter cometido violência contra crianças. Justifica-se que há ocorrências nas quais não se têm testemunhas; portanto, só poderiam ser comprovadas pela palavra dos menores de idade ${ }^{3}$, tornando-se esta a principal e, por vezes, a única prova possível de ser produzida.

Como divulgado em matéria que apresenta o Depoimento sem Dano como

uma inovação do sistema judiciário brasileiro, veiculada pela Revista Época em 
2008: "Onde a técnica é aplicada há seis vezes mais condenaçôes de criminosos" (Aranha, 2008: s/p).

$\mathrm{Na}$ esteira das discussóes sobre o tema, profissionais do direito expressam que não se sentem devidamente capacitados para inquirir menores de idade, considerando que psicólogos e assistentes sociais são os profissionais que devem colher tal testemunho, pois possuem domínio sobre o modo mais adequado de se formular perguntas às crianças e aos adolescentes (Daltoé Cezar, 2007b; Dias, 2007). Entre profissionais do direito encontra-se também a alegação de que o processo penal estaria se modificando em função do reconhecimento da importância de interdisciplinaridade, que pode facilitar o trabalho da justiça, atribuindo-se aos avanços das ciências humanas o fato de o depoimento de crianças e adolescentes ganhar notoriedade no âmbito jurídico. Nesses casos, indicam que, em um testemunho, torna-se tarefa primordial diferenciar verdade de mentira.

Dias (2007) ressalta que, quando a criança se sente constrangida e quando a pessoa que colhe seu depoimento não possui técnica adequada, há tendência de se negar a ocorrência do abuso ou de se absolver o acusado, devido à má qualidade da prova. A autora aponta, também, que podem ser desconsideradas conclusóes de estudos realizados em casos nos quais não houve o depoimento da vítima em juízo. Dias (2007) explica que: "mesmo que o abuso reste comprovado por meio de estudo social ou perícia psicológica ou psiquiátrica, sempre resta a alegação de que, na primeira oportunidade em que foi ouvida, a vítima negou a ocorrência da situação de violência" (Dias, 2007: 48).

Admite-se também que o ambiente das salas de audiência não contribui para deixar crianças à vontade para depor, principalmente porque naquele local se encontram diversas pessoas, dentre elas o próprio acusado. Matéria publicada em 2007 no portal de notícias 24 horas news, de Mato Grosso, destaca a instalação, no Fórum de Cuiabá, de sala especialmente projetada para a realização do Depoimento sem Dano, sendo descrito que naquele espaço há "brinquedos espalhados pelo chão, quadros coloridos nas paredes, almofadas, tapetes, mesinha, cadeiras, lápis de cor, pincéis, canetinhas". Justifica-se a adequação da sala: "para deixar a vítima mais à vontade, ela será ouvida com a ajuda de um facilitador, ou seja, um profissional de serviço social ou psicólogo. Ele vai transmitir as perguntas do magistrado, sem que a criança ou adolescente perceba que está em uma audiência” (24 Horas News, 2007: s/p).

Nessas circunstâncias, vem sendo lembrado que o depoimento geralmente acontece mais de uma vez ao longo do processo, fato que contribuiria para revitimizar crianças e adolescentes. Por esse motivo, alguns alegam que o Depoimento sem Dano seria uma maneira de evitar constrangimentos às crianças, ga- 
rantindo-se a qualidade do depoimento e o fácil acesso a este nas diferentes etapas do processo. Defendem que esta prática garantiria, também, o direito de crianças e de adolescentes terem sua palavra valorizada.

Os que se posicionam como favoráveis à prática a conceituam como uma nova, moderna, eficiente, rápida e pouco dispendiosa forma de inquirição de crianças e adolescentes, qualidades muito valorizadas na "modernidade líquida", expressão usada por Bauman (2001) para definir o contexto contemporâneo ocidental.

Daltoé Cezar (2008) recorda que outros países vêm utilizando técnicas similares ao Depoimento sem Dano, citando o modelo argentino, o espanhol e o francês. Assim, saúda o Projeto de Lei 035/2007, que dispõe sobre a forma de inquirição de crianças e adolescentes testemunhas e a produção antecipada de provas.

Pode-se recordar que no denominado caso Isabella, que ocorreu em São Paulo em abril de 2008, o Ministério Público aventou a hipótese de ouvir o irmão, de 3 anos de idade, da menina. Em notícia publicada pela imprensa, encontra-se a justificativa de que "o garoto seria uma testemunha-chave para ajudar a polícia a desvendar o crime” (Borges, 2008: s/p). Na mesma matéria, foi destacado que o promotor do caso sugeriu que o menino fosse ouvido em condiçóes especiais e com a presença de psicólogos, argumentando que esta prática vem sendo adotada desde 2003, no Rio Grande do Sul, em programa denominado Depoimento sem Dano.

Não é de se estranhar, portanto, que a obtenção do testemunho de crianças e de adolescentes venha acarretando longos debates nos últimos tempos, mormente entre psicólogos e profissionais da área jurídica. Destarte, travam-se na atualidade fortes discussōes entre profissionais, enfocando-se e analisando-se critérios éticos, teóricos, metodológicos e técnicos a partir de referenciais que parecem não ser os mesmos, causando por vezes incompreensões. Como argumenta Daltoé Cezar (2008), em entrevista ao Boletim do Instituto Brasileiro de Direito de Família (IBDFAM): "O Conselho Federal de Psicologia, no ano que passou, encaminhou uma moção contrária à aprovação do Projeto que já tramita no Senado [...]. Tivessem tido a responsabilidade de conhecer o trabalho, não teriam feito essas afirmações" (Daltoé Cezar, 2008: 4).

Destaca-se, no entanto, que os debates levados a termo sobre o assunto têm acontecido também entre psicólogos. Para Trindade (2007), por exemplo, possíveis críticas à técnica do Depoimento sem Dano se devem ao fato de ser esta uma proposta nova que acarretaria incertezas e ansiedade, pois, segundo o autor, "de alguma maneira nos aferramos ao conhecido: resistimos à mudança, pessoal, social e institucionalmente" (Trindade, 2007: 10). 


\section{Algumas CONTESTAÇÕES À IMPLANTAÇÃo DO DEPOIMENTO SEM DANO}

Cabe destacar inicialmente que a moção encaminhada pelo Conselho Federal de Psicologia ao Senado Federal em 2007, citada por Daltoé Cezar (2008), funda-se na compreensão de que tal tarefa "não diz respeito à prática psicológica". Há entendimento do órgão de representação dos psicólogos de que esta técnica distancia-se do trabalho a ser realizado por um profissional de psicologia, acarretando confusão de papéis ou indiferenciação de atribuições, quando se solicita ao psicólogo que realize audiências e colha testemunhos.

Sem desconsiderar a difícil situação da criança que passa por reiterados exames em processos dessa ordem, nota-se que, na proposta em análise, na inquirição a ser feita por psicólogo não há objetivo de avaliação psicológica, bem como de atendimento ou encaminhamento para outros profissionais, estando presente, apenas, o intuito de obtenção de provas jurídicas contra o acusado.

Visão semelhante encontra-se disposta em parecer elaborado por Fávero (2008), mediante solicitação do Conselho Federal de Serviço Social sobre a metodologia do Depoimento sem Dano:

a atuação do assistente social como intérprete da fala do juiz na execução da metodologia do DSD não é uma prática pertinente ao Serviço Social. A própria terminologia utilizada na proposta deixa claro que se trata de procedimento policial e judicial, como depoimento, inquirição etc., pertinentes à investigação policial e à audiência judicial (Fávero, 2008: s/p).

Dando prosseguimento ao debate travado pela categoria dos psicólogos, em 9 de abril de 2008 o Conselho Federal de Psicologia publicou em sua página eletrônica manifesto sobre o assunto, assinado por seu Presidente e pela Presidente da Comissão Nacional dos Direitos Humanos do referido Conselho, no qual se pode destacar:

O Conselho Federal e a Comissão Nacional de Direitos Humanos sugerem que a Justiça construa outros meios de montar um processo penal e punir o culpado pelo abuso sexual de uma criança ou adolescente, pois não será pelo uso de modernas tecnologias de extração de informaçōes, mesmo com a presença de psicólogos supostamente treinados, fora de seu verdadeiro papel, que iremos proteger a criança ou o adolescente abusado sexualmente e garantir seus direitos (Conselho Federal de Psicologia, 2008a: s/p).

Em maio de 2008, o Jornal do Conselho Federal de Psicologia apresenta a matéria "CFP é contra Depoimento Sem Dano", na qual são explicitados pontos 
abordados no documento acima destacado, ressaltando-se que "a criança não pode ter o dever de depor na Justiça”" (Conselho Federal de Psicologia, 2008b: 10). Em primeiro de julho de 2008, em audiência pública realizada no Senado Federal, a professora Esther Arantes (2008), ao representar o Conselho Federal de Psicologia, tece valiosas observações sobre o Projeto, alertando sobre os diversos entendimentos a respeito do que seria a proteção integral da criança que parecem dispostos nas discussóes travadas em torno do tema.

No estudo da matéria, cabe recordar que a primeira grande articulação entre o Direito e a Psicologia teve origem a partir da necessidade jurídica de obtenção de testemunhos e de avaliação da fidedignidade destes, como citado por Mira y López (1967).

Foi justamente a proposta de se aplicar, em investigaçôes criminais, métodos utilizados por profissionais da Psicologia que motivou Freud a esclarecer, em conferência proferida em 1906 para estudantes de Direito, que a simples transposição de técnicas e experiências psicológicas à prova legal para obtenção de testemunhos não seria indicada, referindo-se especificamente à denominada experiência de associação. Freud ([1906] 1974) ressalta que o campo em que se pretendia empregar aquela experiência era distinto do contexto no qual esta vinha sendo aplicada, bem como apresentava objetivos diferenciados. Por esse motivo, recomendou que a técnica não fosse utilizada para fundamentar processos criminais.

Explica Freud ([1906] 1974) que, se no âmbito da psicanálise, por exemplo, a proposta com o paciente seria "descobrir o material psíquico oculto" (Freud, [1906] 1974: 59), em uma investigação levada a termo nos tribunais a necessidade seria a de se "obter uma convicção objetiva" (Freud, [1906] 1974: 62) do fato em julgamento. Indaga, assim, se a preocupação da pessoa em ocultar algo durante o depoimento não poderia gerar distintas formas de reação. Seguindo esse raciocínio, no caso do Depoimento sem Dano causa certo estranhamento o fato de se defender o uso, no espaço jurídico, de dispositivo empregado por alguns psicólogos no contexto clínico, como a chamada Câmara de Gesell, sem levar em consideração diferenças contextuais e os objetivos de cada intervenção.

No procedimento denominado Depoimento sem Dano, nota-se que a urgência para a tomada de decisões mostra-se clara ao se determinar que, em um único encontro, a questão deve ser elucidada, limitando-se o direito de a criança ser ouvida. Nessas circunstâncias, percebe-se que não há tempo para entrevistas com responsáveis, com o suposto abusador e para estudos psicológicos acerca do caso. Estas se tornam situações nas quais pais e filhos passam a ser tratados sob a ótica de agressores e vítimas, desconsiderando-se, por vezes, toda a dinâmica familiar na qual estão incluídos. Melhor dizendo, a dimensão familiar da situação é 
vista apenas como possibilidade de agravante da pena, como disposto na alínea "e", inciso II, do artigo 61 do Código Penal Brasileiro.

No estudo da violência cometida contra crianças, pesquisadores - como Camdessus (1993) - indicam que a avaliação sobre a suspeita de violência sexual deve ser minuciosa, com metodologia rigorosa para que se possa analisar se a denúncia possui fundamento, não sendo possível desconsiderar que a avaliação ocorrerá, justamente, quando a família se encontra em momento de crise devido à natureza da denúncia. A autora aponta também para a necessidade de se redobrar a prudência em situações onde existam sérias divergências entre os pais da criança, como nas disputas pela guarda ou visitação. Afirma, ainda, que não se deve desprezar o dado de que, no caso de o abuso ter sido praticado pelo pai, "freqüentemente a criança abusada o ama e o detesta ao mesmo tempo", motivo pelo qual: " $85 \%$ das vítimas meninas querem ver cessar o abuso sexual, mas não desejam necessariamente envolver seu pai na prisão" (Camdessus, 1993: 106).

Azambuja (2006), Procuradora de Justiça no Rio Grande do Sul, também aconselha que se evite "buscar a prova de materialidade nos crimes que envolvem violência sexual intrafamiliar através do seu depoimento” (da criança), ressaltando a importância de uma escuta especializada nos atendimentos feitos por psicólogos e assistentes sociais (Azambuja, 2006: s/p). Na visão desta autora, ouvir a criança é distinto de se colher o depoimento desta visando à produção de provas. Reconhece, ainda, que o “direito de ser 'ouvida' como prevê o artigo 12 da Convenção Internacional sobre os Direitos da Criança, não tem o mesmo significado de ser "inquirida"' (Azambuja, 2008: 15).

Na prática em análise, podem ser levantadas outras interrogaçōes como, por exemplo, se a não-vitimização da criança ocorreria apenas pelo fato de se evitar o depoimento desta na frente do acusado e de não ser solicitado que forneça depoimento em distintas ocasióes. Parece pertinente também questionar se estaria sendo desconsiderada a menoridade jurídica de crianças e de adolescentes, equiparando-se o direito de ser ouvido à obrigação de testemunhar. Como é de amplo conhecimento, a legislação, ao considerar crianças e adolescentes como incapazes, se refere à incapacidade jurídica, ou seja, objetivando a proteção destes, que não podem ter as mesmas responsabilidades e deveres legais dos maiores de idade.

Caberia argüir, ainda, se as crianças irão assumir o compromisso de dizer somente a verdade e o que lhes ocorrerá caso não o façam. Pode-se indagar, também, o que seria a verdade para uma criança. Recordando o caso Isabella, pode-se perguntar se os pais ou os responsáveis por uma criança poderão se opor à determinação de que seus filhos testemunhem. A criança, ao ser inquirida, compreenderia as conseqüências de suas declarações? Como se sabe, crianças possuem difi- 
culdades para entender ou diferenciar situações carinhosas das ocorrências caracterizadas como abuso, até porque o abuso pode acontecer sem violência física. $\mathrm{Da}$ mesma forma, se observa que a criança, por vezes, não possui clareza sobre o fato que vivenciou, repetindo histórias que lhe foram contadas por pessoas de sua confiança, com quem mantém laços de afeto, reproduzindo fielmente afirmações que lhe foram transmitidas.

No que diz respeito ao caso acima citado, cabe recordar que, em 8 de maio de 2008, o Conselho Nacional dos Direitos da Criança e do Adolescente (Conanda) emitiu nota pública na qual indicava posicionamento contrário à participação de criança de três anos como testemunha em processo criminal no Tribunal do Júri. Dentre as justificativas elencadas para não se inquirir a criança no caso em questão, encontra-se citação do artigo 206 do Código de Processo Penal, o qual prevê que pais, mães, filhos e cônjuges de acusados podem se eximir da obrigação de depor. Há também referência ao artigo 208 do mesmo diploma, o qual dispõe que a testemunha de menos de 14 anos não presta compromisso, não sendo obrigada a depor. É feita menção, ainda, ao fato de que, no Rio Grande do Sul, crianças são ouvidas na condição de vítimas e não de testemunhas, concluindo-se que "inquirir qualquer criança é algo polêmico e muito delicado".

\section{UM PANORAMA ESTRANGEIRO}

Destaca-se, inicialmente, que o argumento evocado de que técnica semelhante ao Depoimento sem Dano já ocorre em outros países não significa que tenha havido consenso para esta implantação. Pode-se afirmar que a indicação de que assistentes sociais e psicólogos seriam profissionais apropriados para realizar a inquirição de crianças tem sido motivo de polêmica em outros países, como na Argentina, onde o Código de Processo Penal foi alterado em 2004 para que essa prática fosse possível. Como noticiado no Diário Rio Negro, em 4 de dezembro de 2006, houve desacordo por parte dos psicólogos argentinos em relação à alteração da lei, especialmente por considerarem que o uso da Câmara de Gesell no contexto jurídico distorce o trabalho dessa categoria profissional.

$\mathrm{Na}$ África do Sul, como apontam Jonker e Swanzen (2006), um sistema de obtenção do testemunho infanto-juvenil é adotado desde 1993. Os autores descrevem a existência de procedimentos e condiçôes semelhantes às que foram implantadas no Rio Grande do Sul, explicando que:

um circuito fechado de televisão, um microfone e o intermediador formam a base do sistema. Há um receptor de televisão na sala principal do tribunal, e 
uma sala com uma câmera, que fica adjacente a esta sala principal do tribunal, acomoda a criança-testemunha e o intermediador. Este fica com fones de ouvido. Somente o intermediador ouve as perguntas, mas as pessoas presentes na sala do tribunal ouvem as respostas e qualquer coisa que se passe na sala da testemunha (Jonker \& Swanzen, 2006: s/p).

Esclarecem ainda que, no projeto proposto, estava previsto que o profissional encarregado de transmitir as perguntas às crianças poderia adequar as questóes para que estas estivessem de acordo com o entendimento de uma criança, porém deveria tomar cuidado para que o sentido da questão não fosse alterado. Caberia também a esse profissional avisar ao juiz quando percebesse cansaço ou falta de concentração na criança. No citado artigo há, entretanto, informação de que, naquele país, quem transmite as perguntas possui um reduzido poder de ação, sendo percebido, na verdade, como um intérprete do juiz. Não é usual, por exemplo, a possibilidade de o intermediador apontar algumas questões como inadequadas, ou recomendar mudanças na seqüência de perguntas. Há considerações no artigo quanto à possibilidade de este contexto estar causando danos à criança.

Mencionam também no artigo o fato de que, após a adoção desse sistema para coleta de testemunho, qualquer atendimento psicoterápico com a criança que se supõe vítima de abuso sexual só pode ser iniciado após o depoimento da criança no Tribunal, a fim de que não haja qualquer interferência no relato. No entanto, o depoimento, por vezes, não ocorre logo, deixando-se crianças sem atendimento psicológico em nome da eficácia do processo. Explicam ainda que, apesar de inicialmente haver previsão de serviços destinados ao atendimento psicológico dessas crianças, na realidade poucos são oferecidos. Sendo assim, por vezes se tem a impressão de que o depoimento da criança é valorizado exclusivamente para o castigo ou punição do autor, ficando em segundo plano o atendimento de que a criança necessita.

A psicóloga Marlene Iucksch, em palestra proferida na Universidade do Estado do Rio de Janeiro em 2007, ressaltou que procedimento similar ao Depoimento sem Dano é empreendido na França por policiais que, devidamente treinados, auxiliam a instrução do processo. Foi com surpresa que a citada psicóloga recebeu a informação de que, no Brasil, se propõe que psicólogos realizem esta tarefa. Na visão de Marlene, esta atuação não seria própria a psicólogos, haja vista que a verdade psicológica é distinta da verdade jurídica. Para ela, o psicólogo deve estar atento à escuta da subjetividade, não lhe cabendo ser intérprete da verdade jurídica. Além do que, compreende que reconhecer o direito de a criança se expressar é diferente de se sacralizar a palavra desta. 


\section{Conclusão}

Ao considerar os argumentos expostos como justificativas para a implantação do Depoimento sem Dano em território nacional, soa como evidente o intuito de busca de métodos objetivos, precisos, seguros, verídicos, incontestáveis, provas consistentes que forneçam sustentação à apuração do fato e à posterior condenação do abusador. Agora, entretanto, psicólogos e assistentes sociais seriam responsáveis por colher tais evidências.

Apesar de ser corrente, na bibliografia consultada, a alegação de que atualmente as crianças que vêm sendo ouvidas por profissionais que realizam o Depoimento sem Dano estejam na condição de vítimas, torna-se importante destacar que o projeto de lei em apreço faz menção à inquirição de crianças tanto na condição de vítimas como na de testemunhas. Portanto, se poderia supor que, se aprovado, não haveria impedimento para se determinar o depoimento de criança de três anos de idade, principalmente quando alegado que ela seria testemunhachave de crime ocorrido.

No caso citado, cabe destacar que a possibilidade de depoimento do irmão da vítima - criança de tenra idade que teve toda a sua rotina afetada por conta da morte da irmã e da acusação e prisão dos pais - surge justamente na hora em que é feita contestação à perícia técnica realizada. Conclui-se assim que, no momento em que as provas técnicas são vistas com suspeição, quando não se consegue obter a confissão do pai e da madrasta quanto à possível participação no crime e quando surgem indícios de falhas na apuração deste, é que desponta a idéia de o menino ser convocado a depor. Poder-se-ia, em resumo, admitir que, quando todos os adultos que se ocupam do caso não sabem mais o que fazer para elucidar o crime, convoca-se a criança! Agora, entretanto, o seu direito de se expressar será transformado em obrigação de testemunhar.

Conclui-se, portanto, que além de esta não ser uma tarefa para psicólogos, a partir da concepção que se tem da Psicologia a revitimização da criança pode ocorrer tanto pela ausência como pelo excesso de intervençôes, bem como por intervençôes inadequadas. Compreende-se que, a despeito do intuito protetor que tenha motivado o projeto de lei, este pode se revelar prejudicial às crianças e adolescentes. 


\section{REFERÊNCIAS BIBLIOGRÁFICAS}

Aranha, A. (2008). Em defesa das crianças. Disponível em <http://revistaepoca.globo.com/ Revista/Epoca/O,EDR80881-6009,00.html>. Acesso em 10 março de 2008.

Arantes, E. (2008). Discurso de Esther Arantes em Audiência Pública no Senado Federal sobre o Depoimento sem Dano. Disponível em <http://www.pol.org.br/pol/cms/pol/debates/ direitos_humanos_080829_001.html>. Acesso em 29 agosto de 2008.

Azambuja, M. R. F. (2006). Violência sexual intrafamiliar: é possivel proteger a criança? Disponível em <http://www.mp.rs.gov.br/infancia/doutrina/id500htm>. Acesso em 3 março de 2008.

. (2008). Quando a criança é vítima: a quem compete produzir a prova? Jornal Zero Hora, 3 de maio de 2008, p. 15.

Bauman, Z. (2001). Modernidade líquida. Rio de Janeiro: Jorge Zahar.

Borges, D. (2008). Defesa de Nardoni é contra depoimento de irmão de Isabella. Disponível em http://oglobo.globo.com/sp/mat/2008/05/01/defesa_de_nardoni_contra_ depoimento_de. Acesso em 01 maio de 2008.

Camdessus, B. (1993). Violences au présent. Em Camdessus, B. \& Kiener, M. L'enfance violentée (pp. 93-176). Paris: ESF Éditeur.

Conselho Federal de Psicologia (2008a). Conheça a manifestação do Conselho sobre o PL que trata do Depoimento sem Dano. Disponível em <http://www.pol.org.br/pol.cms/ pol/noticias/noticia_080409_932.htm>. Acesso em 9 abril de 2008.

Conselho Federal de Psicologia (2008b). CFP é contra o Depoimento sem Dano. Jornal do Federal, 89, 10, 10.

Daltoé Cezar, J. A. (2007a). A criança vítima de abuso sexual pode ser inquirida em juízo de forma humanizada? Em Oliveira, A. C. \& Fernandes, N. C. (Orgs.). Violências contra crianças e adolescentes: redes de proteção e responsabilização (pp. 55-71). Rio de Janeiro: Nova Pesquisa e Assessoria em Educação.

. (2007b). Depoimento sem Dano: uma alternativa para inquirir crianças e adolescentes nos processos judiciais. Porto Alegre: Livraria do Advogado Editora.

. (2008). Depoimento sem Dano. Boletim do Instituto Brasileiro de Direito de Família, 48, 3- 4.

De Paulo, A. (ed.). (2005). Pequeno dicionário jurídico. Rio de Janeiro: DP\&A.

Diário Rio Negro. (2006). Los psicólogos cuestionan la Cámara Gesell. Disponível em <http:/ /www.rionegro.com.ar/diario/2006/12/04/200612r04f01.php>. Acesso em 04 de outubro de 2008.

Dias, M. B. (2007). Incesto e o mito da família feliz. Em Dias, M. B. (Org.). Incesto e alienação parental: realidades que a Justiça insiste em não ver (pp. 17-50). São Paulo: Editora Revista dos Tribunais. 
Estatuto da Criança e do Adolescente. Lei Federal no 8069 de 1990.

Fávero, T. E. (2008). Parecer técnico: metodologia "Depoimento sem Dano", ou "Depoimento com Redução de Danos". Disponível em http://www.cress- sp.org.br/index. asp?fuseaction=manif\&id=162. Acesso em 15 de junho de 2008.

Freud, S. (1906). A psicanálise e a determinação dos fatos nos processos jurídicos. Obras completas, ESB, v. IX. Rio de Janeiro: Imago, 1974.

Jonker, G. \& Swanzen, R. (2006). Serviços de intermediação para crianças-testemunhas que depõem em tribunais criminais da África do Sul. Disponível em <http:// www.surjournal.org/conteudos/artigos 6/port/artigo_jonker.htm>. Acesso em 8 de agosto de 2007.

Mira y López, E. (1967). Manual de Psicologia Jurídica. São Paulo: Mestre Jou.

Senado Federal. Projeto de Lei Complementar 35/2007.

Secretaria Especial dos Direitos Humanos (2008). Conanda se posiciona contra depoimento do irmão de Isabella Nardoni. Disponível em <http://www.presidencia.gov.br/ estrutura_presidencia/sedh/noticias/ultimas_noticias>. Acesso em 17 de maio de 2008.

Théry, I. (1998). Couple, filiation et parenté aujourd'hui. Le droit face aux mutations de la famille et de la vie privée. Paris: Odile Jacob/La Documentation Française.

Trindade, J. (2007). Prefácio. Em Daltoé Cezar, J. A. (2007). Depoimento sem Dano: uma alternativa para inquirir crianças e adolescentes nos processos judiciais (pp. 9-13). Porto Alegre: Livraria do Advogado Editora.

24 Horas News (2007). Crianças vítimas de abuso sexual ganham sala especial para depoimentos. Disponível em <http://www.24horasnews.com.br/index.php?tipo=ler8mat= 226447>. Acesso em 07 agosto de 2008.

\section{Notas}

1 Inquirição: "O ato de a autoridade competente indagar da testemunha o que ela sabe acerca de determinado fato que tenha presenciado ou do qual tenha tomado conhecimento" (De Paulo, 2005: 190).

2 Encontra-se também a denominação "depoimento com redução de danos" e "depoimento especial", como sinônimos de Depoimento sem Dano.

3 Daltoé Cezar (2007a: 57) refere-se a "inquirição, escuta ou ouvida da criança em juízo", aparentemente como sinônimos.

Recebido em 05 de julho de 2008 Aceito para publicação em 01 de setembro de 2008 